\title{
Who Wants a Seat at the Table for Dietary and Climate Change Strategies?
}

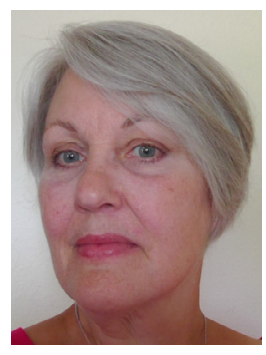

As I sit, in July, in temperatures over $100^{\circ} \mathrm{F}$ and breathe smokefilled air, I am thinking about climate change and what that means for our future. Channeling my thoughts into more productive realms, I have been thinking about my role, both personally and professionally, and how I can positively contribute to the future of the planet. I am contemplating moving toward a more plant-based diet and how far I, and my household, are willing to step in that direction.

Food production and consumption contribute substantially to greenhouse-gas emissions and water usage. ${ }^{1}$ Estimates suggest that agriculture dwells on about $40 \%$ of earth's surface and food production accounts for $30 \%$ of greenhouse gases. $^{2}$ Moreover, food production accounts for nearly $70 \%$ of freshwater use. ${ }^{3}$ Plainly put, what we grow, what we eat, and what we waste have strong impacts on environmental shifts related to climate change.

Calls are being made for significant changes in how and what we eat. The EAT-Lancet Commission ${ }^{4}$ brought attention to how diets are inequitable when considered globally, and how diets are "inextricably linked to human health and environmental sustainability." The point has been made that the global population, far from static, will likely grow to 10 billion people by the year 2050; further increasing the demand on resources and the environment.

The EAT-Lancet Commission undertook the estimation of dietary patterns that would both address global inequities in availability of nutritious foods and that could reduce the burden upon the environment. These reference dietary patterns are offered in efforts to decrease noncommunicable disease and are based upon estimations of appropriate energy intake, plant-based, low in animal source foods, and limited with respect to highly processed foods (eg, foods lower in added sugars, refined grains, and sodium). The expectation is that adoption of these dietary patterns will reduce global consumption of highly processed, less healthy foods by $50 \%$ and increase consumption of healthful foods (nuts, grains, fruits, and vegetables) by $100 \%$. Such changes are projected to result in improvements in human health while reducing the toll on land and water use.

The proposed changes in dietary patterns would demand major changes in intake for a majority of the world's population. Notably, the international commission that produced the projections consisted of nutrition epidemiologists and experts in human health, agriculture, political science, and environmental sustainability. Less prominent was the presence of nutrition educators and behavior scientists and practitioners. This begs the question of how individuals will be educated and motivated to (willingly) adopt such dietary and cultural changes.
A long history of complex nutrition interventions has taught us that nutrition education and behavior change theories and practice are critical to the design and implementation of successful interventions that actually produce the desired behavior change(s). Thus, an opportunity exists for nutrition educators to lean in and be leaders in developing effective strategies and programs to address the coming demands for global change. Nutrition educators and behavioral scientists have unique and important skills to contribute to these efforts. Perhaps it is time to seize the day.

Susan L. Johnson, PhD Senior Associate Editor

\section{REFERENCES}

1. Foley JA, Defries R, Asner GP, et al. Global consequences of land use. Science. 2005;309:570-574

2. Vermeulen SJ, Campbell BM, Ingram JSI. Climate change and food systems. Annu Rev Environ Resour. 2012;37:195222.

3. Comprehensive assessment of water management in agriculture. Water for Food, Water for Life: A Comprehensive Assessment of Water Management in Agriculture. Earthscan and Colombo: International Water Management Institute; 2007.

4. Willett W, Rockström J, Loken B, et al. Food in the Anthropocene: The EAT -Lancet Commission on healthy diets from sustainable food systems. Lancet. 2019;393:447-492. 